\title{
Teenage mothering, admission to hospital, and accidents during the first 5 years
}

\author{
B TAYLOR, J WADSWORTH, AND N R BUTLER \\ Child Health and Education Study, Department of Child Health, University of Bristol
}

\begin{abstract}
SUMMARY One thousand and thirty-one singleton children of teenage mothers were compared with 10950 singleton children of older mothers in a national longitudinal cohort study. Children born to teenage mothers and living with them during the first 5 years were more liable to hospital admissions, especially after accidents and for gastroenteritis, than were children born to and living with older mothers. Frequent accidents, poisoning, burns, and superficial injuries or lacerations were more often reported by teenage mothers. The association of teenage mothering with greater likelihood that children would have accidents or be admitted to hospital remained highly significant even after controlling for social and biological confounding influences. Although in part a marker for adverse socioeconomic circumstances, low maternal age appears to be a health hazard for children.
\end{abstract}

Teenage pregnancy has been associated with a variety of problems including increased risk of anaemia, toxaemia, urinary tract infection, uterine dysfunction, cephalo-pelvic disproportion, abruptio placentae in the mother, and preterm delivery and low birthweight in the child together with high rates of fetal, perinatal, and maternal mortality. ${ }^{1-3}$

Disadvantage continues for the child after birth. Infant mortality is higher than average ${ }^{4}$ and the children of young mothers have been shown to suffer more physical, emotional, and intellectual handicaps than do others. ${ }^{5}$ They are also liable to poorer educational attainment ${ }^{6}$ and behavioural disturbances. ${ }^{7}$

Despite an expansion of research on the topic, especially in the USA, ${ }^{8-11}$ it is not known whether the child born to a teenage mother is also at higher risk of infections or other causes of morbidity. Most studies have investigated psychological development and behaviour outcomes of the child or explored the problems of the mother.

Much of the ill effect associated with low maternal age may not be a direct effect but due to the frequently accompanying illegitimacy, low socioeconomic status, poor housing and social environment, low educational attainment, lack of support, and inexperience.

In this study we have compared certain health outcomes in the early life of a group of children born to teenage mothers with those born to older mothers using information from a national birth cohort.

\section{Subjects and methods}

The Child Health and Education Study is an ongoing survey of children studied at birth in the British Births Survey. ${ }^{12} 13$ The cohort included originally all children born in the UK including Northern Ireland between 5 and 11 April 1970 inclusive. In 1975 all children were traced who were born in that week and living in England, Scotland, or Wales; $12743(79.6 \%)$ subjects were studied out of a possible 16015 survivors from the birth survey.

At the birth interview information was gathered, inter alia, on marital status, maternal age at delivery, and smoking habits during pregnancy as well as on the birthweight of the child, and presence of any neonatal problems. At age 5, health yisitors gathered a wide range of social, family, and health data (over 500 items) at a home interview with the mother. These included:

(1) Number of admissions to hospital with reasons and diagnoses. From this, 4 groups were selected: (a) any admission, (b) after accidents, (c) gastroenteritis, (d) lower respiratory illness including wheezing, bronchitis, bronchiolitis, and pneumonia.

(2) Details of all accidents including those not resulting in admission to hospital. These were classified (a) by type: poisoning, burn, superficial injury or laceration, head injury (not necessarily concussion), fracture or dislocation, miscellaneous other accidents; (b) by place: at home, 
outdoors, at nursery school*, or in a traffic accident.

The following influences derived from the birth or 5-year interviews were used as control variables in multivariate analyses: the child's gender, birthweight $(<2500$ or $\geqslant 2500 \mathrm{~g}$ ), birth rank (only child in the household at 5 , older siblings, younger siblings, or younger and older siblings), the number of times the family moved house in the child's first 5 years $(0-1, \geqslant 2)$, maternal smoking (average number of cigarettes smoked each day during pregnancy-none, $1-4,5-14, \geqslant 15$ ), the family type at 5 years ( 2 natural parents, other), and the family social index, ${ }^{14}$ which is a composite assessment of socioeconomic status including domestic crowding, parental education, tenure of accommodation, type of neighbourhood, and paternal occupation (advantaged, average, disadvantaged). Factors were initially chosen on empirical grounds as being likely to contribute to the condition being assessed. The final multivariate model contained only those factors having greatest influence.

The current report analyses information on singleton born children living with their natural mothers at 5 years for whom linked data were available from the birth interview and at 5 years. There were 1031 singleton births to teenage mothers and 10950 singleton births to older mothers. Details of the study population, together with numbers eligible from the British Births Survey 1970 and deaths in that population to age 5 years are shown in Table 1. The total births column excludes children from Northern Ireland, as there has been no subsequent survey there. It can be seen that the proportion of eligible children from the birth study surveyed at 5 was rather lower in the two teenage mother groups ( $<18$ and $18-19$ years) than in the four older mother groups. This was associated with the fact that fewer children of mothers who were

*In this paper the term 'nursery school' includes playgroups, nursery classes, day nurseries, kindergartens, and early entry to infant school. single at the birth of the child were followed up at 5 , than children of married mothers. Because the sample was incomplete the results cannot be assumed applicable to all children born to teenage mothers, many of whom were adopted, fostered, or brought up by grandparents.

In cases where there was missing information (never more than $5 \%$ for any variable and generally less than $1 \%$ ) as complete a data set as possible was used in each analysis. Initial analysis included twoway tabulations usually separating maternal age into the six groups and $\chi^{2}$ statistics comparing all teenage with all other mothering. For multivariate analyses, logistic analysis of multiway contingency tables was carried out ${ }^{15}$ using the statistical package GLIM ; ${ }^{16}$ the individual contribution of factors and their possible interactions in the multivariate analyses were assessed by the log likelihood $\chi^{2}$ statistic.

\section{Results}

Table 2 shows the association of teenage mothering with the social and biological variables used in the

Table 2 Associations of teenage compared with other mothering

\begin{tabular}{|c|c|c|}
\hline & \multicolumn{2}{|c|}{ Age of mother (years) } \\
\hline & $<20$ & $\geqslant 20$ \\
\hline \multicolumn{3}{|l|}{ Social index $(\%)$} \\
\hline Advantaged & $14 \cdot 9$ & $38 \cdot 9$ \\
\hline Average & $40 \cdot 4$ & $36 \cdot 6$ \\
\hline Disadvantaged & $44 \cdot 6$ & $24 \cdot 5$ \\
\hline \multicolumn{3}{|c|}{ Type of neighbourhood (\%) } \\
\hline Poor urban & $11 \cdot 9$ & $7 \cdot 2$ \\
\hline Other & $88 \cdot 1$ & 92.8 \\
\hline \multicolumn{3}{|c|}{ Household moves $0-5$ years $(\%)$} \\
\hline 0,1 & $52 \cdot 6$ & $81 \cdot 6$ \\
\hline$\geqslant 2$ & $47 \cdot 4$ & $18 \cdot 4$ \\
\hline \multicolumn{3}{|l|}{ Siblings at $5(\%)$} \\
\hline None & $18 \cdot 2$ & $9 \cdot 4$ \\
\hline Older & $8 \cdot 8$ & $48 \cdot 2$ \\
\hline Older and younger & $10 \cdot 5$ & $16 \cdot 8$ \\
\hline Younger & $62 \cdot 5$ & $25 \cdot 6$ \\
\hline \multicolumn{3}{|l|}{ Family type at $5(\%)$} \\
\hline 2 natural parents & $80 \cdot 6$ & $92 \cdot 1$ \\
\hline Other & $19 \cdot 4$ & 6.9 \\
\hline
\end{tabular}

Table 1 Study population derived from the eligible children in the British Births Survey 1970

\begin{tabular}{|c|c|c|c|c|c|c|}
\hline \multirow[t]{2}{*}{ Mothers' age (years) } & \multicolumn{2}{|c|}{ British births 1970} & \multirow[t]{2}{*}{ Died 1970-75 } & \multirow[t]{2}{*}{ Not traced or tested } & \multirow{2}{*}{$\begin{array}{l}\text { Traced and tested } \\
\text { age } 5(\% \text { possible })\end{array}$} & \multirow{2}{*}{$\begin{array}{l}\text { Study population } \\
\text { (singletons with } \\
\text { natural mother) }\end{array}$} \\
\hline & Total* births & Stillborn & & & & \\
\hline $\begin{array}{l}<18 \\
18-19 \\
20-24 \\
25-29 \\
30-34 \\
\geqslant 35 \\
\text { Age not known }\end{array}$ & $\begin{array}{r}454 \\
1172 \\
5876 \\
5069 \\
2504 \\
1374 \\
103\end{array}$ & $\begin{array}{r}8 \\
12 \\
54 \\
61 \\
34 \\
37 \\
1\end{array}$ & $\begin{array}{r}12 \\
33 \\
126 \\
90 \\
36 \\
30 \\
2\end{array}$ & $\begin{array}{r}138 \\
300 \\
1129 \\
919 \\
468 \\
291 \\
28\end{array}$ & $\begin{array}{r}296(68 \cdot 2) \\
827(73 \cdot 4) \\
4567(80 \cdot 2) \\
3999(81 \cdot 3) \\
1966(80 \cdot 8) \\
1016(77 \cdot 7) \\
72(72 \cdot 0)\end{array}$ & $\begin{array}{r}263 \\
768 \\
4368 \\
3805 \\
1837 \\
940\end{array}$ \\
\hline Total & 16552 & 207 & 329 & 3273 & $12743(79 \cdot 6)$ & 11981 \\
\hline
\end{tabular}

*Excluding children from the birth survey born in Northern Ireland. 
Table 3 Percentage of children admitted to hospital at least once during their first 5 years by maternal age

\begin{tabular}{|c|c|c|c|c|c|c|c|}
\hline & \multicolumn{7}{|c|}{ Age of mother (years) } \\
\hline & $<18$ & $18-19$ & $20-24$ & $25-29$ & $30-34$ & $\geqslant 35$ & All ages \\
\hline Total number of children & 263 & 768 & 4368 & 3805 & 1837 & 940 & 11981 \\
\hline Ever admitted $(\%)$ & $28 \cdot 5$ & $29 \cdot 9$ & $26 \cdot 4$ & $23 \cdot 7$ & $23 \cdot 7$ & $21 \cdot 2$ & $25 \cdot 0$ \\
\hline After an accident $(\%)$ & $10 \cdot 3$ & $8 \cdot 3$ & $6 \cdot 5$ & $5 \cdot 1$ & $4 \cdot 8$ & $3 \cdot 9$ & $5 \cdot 8$ \\
\hline Gastroenteritis $(\%)$ & $4 \cdot 6$ & $4 \cdot 3$ & $2 \cdot 2$ & $2 \cdot 5$ & $2 \cdot 7$ & $2 \cdot 4$ & $2 \cdot 6$ \\
\hline Lower respiratory illness $(\%)$ & $2 \cdot 7$ & $4 \cdot 6$ & $3 \cdot 7$ & $3 \cdot 4$ & $2 \cdot 6$ & $2 \cdot 3$ & $3 \cdot 4$ \\
\hline
\end{tabular}

multivariate analyses. These two-way tabulations show that families in which the mother had a child while a teenager were more likely to be socially disadvantaged (as measured by the social index), more likely to live in poor urban environments, to move frequently, to have subsequent children, and to be without the natural father (mother single, separated, widowed, or divorced) when the children were 5 years.

Table 3 shows, by maternal age, the proportion of children ever admitted to hospital and the proportions admitted after an accident, with gastroenteritis, or for a lower respiratory illness at least once during the first 5 years. It can be seen that overall rates of admission for any reason were higher in children born to and living with teenage mothers at age 5 than in other children. Rates of admission after accidents or for gastroenteritis showed this same relationship but admissions for lower respiratory illness did not. A statistical comparison of overall rates of hospital admission for teenage compared with older mothering is shown in Table 6 which confirms the increased rates for conditions other than lower respiratory illnesses.

Rates for any accidents, including but not limited to those requiring admission to hospital, and place of accident are shown in Table 4. Teenage mothering was associated with a greater likelihood of children having at least one accident and even more so of children having two or more accidents. Overall comparison of teenage mothering with older mothering (Table 6) demonstrated that the differences were significant. Accidents in the home and outdoors were significantly more likely in association with teenage mothering (Table 6) but rates of traffic accidents and those occurring in nursery school were not influenced by maternal age.

Table 5 shows, by maternal age group, the proportions of children having different types of accidents. Some children were involved in different types of accident but were counted only once for any one type. All types of accident were more likely

Table 4 Percentage of children having any accident, and place of accident by maternal age

\begin{tabular}{|c|c|c|c|c|c|c|c|c|}
\hline & & \multicolumn{7}{|c|}{ Age of mother (years) } \\
\hline & & $<18$ & $18-19$ & $20-24$ & $25-29$ & $30-34$ & $\geqslant 35$ & All ages \\
\hline \multirow{3}{*}{\multicolumn{2}{|c|}{$\begin{array}{l}\text { Total number of children } \\
\text { At least one accident }(\%) \\
2 \text { or more }(\%)\end{array}$}} & 263 & 768 & 4368 & 3805 & 1837 & 940 & 11981 \\
\hline & & $57 \cdot 4$ & $49 \cdot 7$ & $46 \cdot 0$ & $42 \cdot 1$ & $40 \cdot 0$ & $36 \cdot 6$ & $43 \cdot 6$ \\
\hline & & $17 \cdot 5$ & $16 \cdot 4$ & $13 \cdot 6$ & $11 \cdot 5$ & $10 \cdot 2$ & $8 \cdot 4$ & $12 \cdot 2$ \\
\hline \multicolumn{9}{|l|}{ Place of accident } \\
\hline Home & $(\%)$ & $43 \cdot 0$ & $37 \cdot 8$ & $35 \cdot 5$ & $31 \cdot 8$ & $29 \cdot 5$ & $24 \cdot 9$ & $32 \cdot 9$ \\
\hline Outdoors & $(\%)$ & $11 \cdot 0$ & $9 \cdot 6$ & $7 \cdot 2$ & $6 \cdot 5$ & $6 \cdot 8$ & $6 \cdot 4$ & $7 \cdot 1$ \\
\hline Road traffic & $(\%)$ & $2 \cdot 3$ & $2 \cdot 3$ & $2 \cdot 3$ & $1 \cdot 6$ & $2 \cdot 0$ & $2 \cdot 0$ & $2 \cdot 0$ \\
\hline Nursery school & $(\%)$ & 1.9 & $1 \cdot 7$ & 1.4 & $1 \cdot 7$ & $1 \cdot 5$ & $1 \cdot 5$ & $1 \cdot 6$ \\
\hline
\end{tabular}

Table 5 Percentage of children for each type of accident by maternal age

\begin{tabular}{|c|c|c|c|c|c|c|c|}
\hline & \multicolumn{7}{|c|}{ Age of mother (years) } \\
\hline & $<18$ & $18-19$ & $20-24$ & $25-29$ & $30-34$ & $\geqslant 35$ & All ages \\
\hline Poisoning $(\%)$ & $8 \cdot 1$ & $9 \cdot 0$ & $5 \cdot 4$ & $4 \cdot 4$ & $3 \cdot 0$ & $2 \cdot 4$ & $4 \cdot 8$ \\
\hline Burn $(\%)$ & $11 \cdot 4$ & $8 \cdot 9$ & $6 \cdot 2$ & $4 \cdot 9$ & $4 \cdot 9$ & $5 \cdot 7$ & $5 \cdot 8$ \\
\hline Superficial injury or laceration $(\%)$ & $22 \cdot 8$ & $19 \cdot 0$ & $17 \cdot 8$ & $16 \cdot 6$ & $15 \cdot 5$ & $13 \cdot 3$ & $16 \cdot 9$ \\
\hline Head injury $(\%)$ & $19 \cdot 4$ & $17 \cdot 3$ & $17 \cdot 4$ & $16 \cdot 2$ & $14 \cdot 8$ & $12 \cdot 6$ & $16 \cdot 3$ \\
\hline Miscellaneous ( $\%)$ & $5 \cdot 3$ & $4 \cdot 8$ & $4 \cdot 6$ & $4 \cdot 8$ & $4 \cdot 2$ & $3 \cdot 5$ & $4 \cdot 6$ \\
\hline
\end{tabular}


Table 6 Teenage $(<20$ years $)$ compared with older mothering

\begin{tabular}{|c|c|c|c|}
\hline & \multicolumn{2}{|c|}{ Percentage of children } & \multirow[t]{2}{*}{ Significance } \\
\hline & $\begin{array}{l}\text { Teenage } \\
\text { mothers }\end{array}$ & $\begin{array}{l}\text { Older } \\
\text { mothers }\end{array}$ & \\
\hline \multicolumn{4}{|l|}{ Hospital admissions } \\
\hline At least once & $29 \cdot 6$ & $24 \cdot 6$ & $P<0.001$ \\
\hline Accidents & $8 \cdot 8$ & $5 \cdot 5$ & $\mathbf{P}<0.001$ \\
\hline Gastroenteritis & $4 \cdot 4$ & $2 \cdot 4$ & $\mathrm{P}<0.001$ \\
\hline Lower respiratory illness & $4 \cdot 1$ & $3 \cdot 3$ & NS \\
\hline \multicolumn{4}{|l|}{ Number of accidents } \\
\hline $\begin{array}{l}\text { At least one } \\
2 \text { or more }\end{array}$ & $\begin{array}{l}51 \cdot 7 \\
16 \cdot 6\end{array}$ & $\begin{array}{l}42 \cdot 8 \\
12 \cdot 5\end{array}$ & $\begin{array}{l}P<0.001 \\
P<0.001\end{array}$ \\
\hline \multicolumn{4}{|l|}{ Place of accident } \\
\hline Home & $39 \cdot 1$ & $32 \cdot 3$ & $P<0.001$ \\
\hline Outdoor & $10 \cdot 0$ & $6 \cdot 8$ & $\mathbf{P}<0.001$ \\
\hline Road traffic & $2 \cdot 3$ & $2 \cdot 0$ & NS \\
\hline Nursery school & $1 \cdot 7$ & $1 \cdot 6$ & NS \\
\hline \multicolumn{4}{|l|}{ Type of accident } \\
\hline Poisoning & $8 \cdot 7$ & $4 \cdot 4$ & $P<0.001$ \\
\hline Burn & $10 \cdot 3$ & $5 \cdot 5$ & $P<0.001$ \\
\hline $\begin{array}{l}\text { Superficial injuries or } \\
\text { lacerations }\end{array}$ & $20 \cdot 0$ & $16 \cdot 6$ & $\mathbf{P}<0.01$ \\
\hline Head injury & $17 \cdot 8$ & $16 \cdot 1$ & NS \\
\hline Fracture or dislocation & $7 \cdot 9$ & $6 \cdot 7$ & NS \\
\hline Miscellaneous & $4 \cdot 9$ & $4 \cdot 5$ & NS \\
\hline
\end{tabular}

in association with teenage mothering but statistical comparison (Table 6) showed that significant differences occurred only for poisoning, burns, and superficial injuries or lacerations.

To allow for possible confounding factors influencing rates of accident and maternal age a multiway contingency table was prepared including accident rates, maternal age, birthweight, type of neighbourhood, the child's gender, the number of household moves 0-5 years, and the social index. The results of logistic analysis of this table are shown in Table 7 together with the significance values of factors influencing this analysis. Factors increasing the likelihood of frequent $(\geqslant 2)$ accidents in children were: larger families (both younger and older siblings), teenage mothers, poor urban neighbourhood, male gender, and frequent household moves. The social status of the family, reflected by the social index, did not influence the likelihood of frequent accidents; neither in an earlier less explanatory model did family type.

Table 7 shows the results of logistic contingency table analyses in which allowance was made for the possible effect of intervening factors on hospital admissions for accidents and gastroenteritis, together with a list of other factors in the analyses in order of significance. It can be seen that after adjustment there remained a highly significant residual effect which could be attributed to low maternal age. The negative effect seen for both assessments of accident in the results for older mothers after adjustment in part reflects the method
Table 7 Effect of other social and biological influences on the relationship between maternal age and children having at least 2 accidents or being admitted to hospital for accidents or gastroenteritis

\begin{tabular}{|c|c|c|c|c|c|c|}
\hline \multirow[b]{2}{*}{$\begin{array}{l}\text { Maternal age } \\
\text { Total number } \\
\text { of children }\end{array}$} & \multicolumn{2}{|c|}{$\begin{array}{l}\text { At least } \\
2 \text { accidents }\end{array}$} & \multicolumn{2}{|c|}{$\begin{array}{l}\text { Accident } \\
\text { admissions }\end{array}$} & \multicolumn{2}{|c|}{ Gastroenteritis } \\
\hline & $\begin{array}{r}<20 \\
995\end{array}$ & $\begin{array}{r}\geqslant 20 \\
10501\end{array}$ & $\begin{array}{r}<20 \\
1005\end{array}$ & $\begin{array}{r}\geqslant 20 \\
10853\end{array}$ & $\begin{array}{l}<20 \\
1029\end{array}$ & $\begin{array}{r}\geqslant 20 \\
10952\end{array}$ \\
\hline $\begin{array}{l}\text { Unadjusted rates }(\%) \\
\text { Expected proportion } \\
\text { from social and } \\
\text { biological distribution } \\
(\%)\end{array}$ & $\begin{array}{l}16 \cdot 9 \\
12 \cdot 9\end{array}$ & $\begin{array}{l}11 \cdot 8 \\
12 \cdot 1\end{array}$ & $\begin{array}{l}9 \cdot 0 \\
5 \cdot 5\end{array}$ & $\begin{array}{l}5 \cdot 5 \\
5 \cdot 7\end{array}$ & $\begin{array}{l}4 \cdot 4 \\
4 \cdot 0\end{array}$ & $\begin{array}{l}2 \cdot 4 \\
2 \cdot 4\end{array}$ \\
\hline $\begin{array}{l}\text { Residual effect for } \\
\text { maternal age }(\%)\end{array}$ & $4 \cdot 0$ & $-0 \cdot 3$ & $3 \cdot 5$ & -0.2 & 0.4 & $0 \cdot 0$ \\
\hline \multicolumn{7}{|c|}{$\begin{array}{ll}\text { Factors in order of significance: } \\
\text { Birthrank*** } & \text { Household moves*** } \\
\text { Maternal age*** } & \text { Younger siblings*** } \\
\text { Neighbourhood*** } & \text { Social index*** } \\
\text { Gender*** } & \text { Family type*** } \\
\text { Household moves*** } & \text { Maternal age*** } \\
\text { Social index NS } & \text { Gender** }\end{array}$} \\
\hline
\end{tabular}

of analysis but could be taken as an advantage children obtained by not being born to teenage mothers. Factors other than low maternal age increasing the likelihood of hospital admission for accidents were: frequent household moves, younger siblings, disadvantaged social index, family type other than 2 natural parents, and male gender. Admissions for gastroenteritis were more likely with disadvantaged social index, older siblings, atypical family situation, and male gender.

\section{Discussion}

The results of this study suggest that although often a marker for adverse socioeconomic circumstances, low maternal age is of itself a health hazard for children. Even after allowing for possible confounding factors, admissions to hospital for accidents and gastroenteritis were found to be more likely in association with teenage mothering. The possibility that the increased likelihood of accidents in children born to teenage mothers might reflect inadequate maternal supervision, or lack of appreciation of possible dangers to young children is supported by our findings regarding place of accidents. Those occurring in the home and outdoors (excluding traffic accidents) were much more likely in association with teenage mothering; whereas maternal age did not influence the rate of accidents occurring in nursery school where experienced supervision was likely. The findings of no increased risk regarding traffic accidents might reflect the general awareness of 
this danger or perhaps relate to the reduced likelihood of families with very young mothers having a car. Although all types of accidents were more likely, significant differences between teenage and other mothering were seen for accidental poisoning, burns, and superficial injuries or lacerations. These were all likely to occur at home, with implications for the danger of the particular environment or defective supervision of these young children.

The finding of no increased likelihood of admission to hospital for lower respiratory illness was surprising. Lower respiratory illness is associated with low socioeconomic status, poor social environment, and maternal smoking. ${ }^{17}$ All these predisposing factors were more common in teenage compared with other mothers in our study population. The lack of association between lower respiratory illness and teenage mothering will be explored in another publication.

The strong association of low maternal age with admissions to hospital for gastroenteritis (Table 7) is likely to reflect the frequently accompanying adverse socioeconomic and environmental factors, together with lack of experience and poor hygiene. The varying association of the social index with accident rates demonstrates the ubiquity of social influences on morbidity. No association was seen between the social index and likelihood of frequent accidents but social index was a highly significant influence on likelihood of hospital admission after accidents. Although low social class is strongly correlated with accidental death ${ }^{18}$ there is other evidence that less serious accidents are not related to social class. ${ }^{1920}$ A similar discrepancy was seen for the influence of family type (Table 7); there was no significant association with frequency of accidents but a highly significant association with hospital admission for accidents. ${ }^{21}$ These findings suggest that there may be (at least) two forms of accident with differing associations: one, less serious accidents even though repeated and another, more serious, resulting in hospital admission or even death.

Hospital admission in early life may have adverse subsequent effects on children. ${ }^{22}$ This possibility adds a long-term dimension to the disadvantage associated with the increased risk of admission to hospital for children born to teenage mothers in the present study.

The socioeconomic disadvantage associated with teenage mothering did not explain all the differential morbidy demonstrated in the present study (Table 7). Although teenage mothers were more disadvantaged than older mothers, the next most disadvantaged group, in terms of social index, type of neighbourhood, frequency of household moves, and family type at 5 years, was that comprising the oldest mothers, those over 35 years at the birth of the child. Their children had the lowest rate of hospital admission for each of the conditions assessed and the lowest rates of accidents (Tables 3, 4 , and 5). This suggests that maternal youth and inexperience per se play an important part in these morbidity measures. Details of the health and development of children born to 'old' mothers will be presented elsewhere.

It could be argued that the results of the present study do not accurately reflect the situation for teenage mothering because of the larger proportion of missing cases in the teenage compared with the older mother groups at the 5-year follow-up. Overall only $71.9 \%$ of the mothers under 20 from the birth survey were interviewed 5 years later (excluding children known to have died) compared with $80.4 \%$ of older mothers. A postal follow-up of missing cases was carried out in 1977 (A Osborn and N R Butler, unpublished data). An additional 1275 children $(8.0 \%$ of the 16016 presumed live children from the birth survey) were contacted. Compared with those in the present study the 'missing' children were more likely to be living in large, lower social class or unsupported families, in poor neighbourhoods, and to have moved frequently since birth. All these markers of socioeconomic disadvantage were more likely with teenage mothering. Thus the differentials demonstrated related to maternal age are likely to be a minimal estimate of the health disadvantage to children associated with teenage mothering.

In the USA, where the problem of teenage pregnancy is proportionally even greater than in Britain, ${ }^{9}$ various intervention programmes have been instituted. Most have aimed to reduce the obstetric hazards to young mothers and children $;{ }^{17} 18$ others have been set up to reduce the psychosocial disadvantage associated with teenage mothering and less than optimal child development. ${ }^{23} 24$ It is possible that the latter type of intervention programmes may also reduce the health disadvantage of teenage mothering which has been demonstrated in the present study. Infant outcome is likely to be inextricably intertwined with the personal development of the mother. Trial programmes of pre- and postnatal social, medical, and educational support to develop parenting skills appear to be needed to attempt to overcome the health difficulties of children of young mothers and the frequently accompanying illegitimacy, low socioeconomic status, poor housing and social environment, low maternal educational attainment, lack of support, and maternal inexperience. 
We thank the Area Health Authorities, Health Boards, and health visitors throughout England, Scotland, and Wales for co-operation, and previous CHES survey workers for their contribution to the research. B T and J W (in part) are supported by the Riyadh Al Kharj Hospital programme, Saudi Arabia.

This paper was developed from a study of teenage mothering supported by the Department of Health and Social Security. The CHES five year follow up was funded by a Project Grant from the Medical Research Council and additional financial support was received from Action for the Crippled Child and the National Birthday Trust Fund.

\section{References}

1 Knox G E. Teenage mothers: a pediatric and obstetrical group at high risk. Minn Med 1971 ; 54: 701-5.

2 McAnarney E R. Adolescent pregnancy: a national priority. Am J Dis Child 1978;132: 125-6.

3 Magrab P, Danielson-Murphy J. Adolescent pregnancy: a review. J Clin Child Psychol 1979; 8: 121-5.

4 Dott A B, Fort A T. Medical and social factors affecting early teenage pregnancy: a literature review and summary of the findings of the Louisiana Infant Mortality Study. Am J Obstet Gynecol 1976; 125: 532-6.

5 Menken J. The health and social consequences of teenage child-bearing. Fam Plann Perspect 1972; 4: 45-53.

6 Davie R, Butler N, Goldstein H. From birth to seven. London: Longman, 1972.

7 Oppel W C, Royston A B. Teenage births: some social, psychological, and physical sequelae. Am J Public Health $1971 ; 61$ : 751-6.

8 Gunter N G, Labarba R C. Consequences of adolescent childbearing on postnatal development. Int J Behav Dev $1980 ; 3: 193-214$.

9 Phipps-Yonas S. Teenage pregnancy and motherhood: a review of the literature. Am J Orthopsychiatry 1980; 50: 403-31.

10 Baldwin W, Cain V S. The children of teenage parents. Fam Plann Perspect 1980; 12: 34-9, 42-3.
11 Scott K G, Field T, Robertson E G. Teenage parents and their offspring. New York: Grune \& Stratton, 1981.

12 Chamberlain R, Chamberlain G, Howlett B, Claireaux A. British births 1970. Vol. 1. The first week of life. London: Heinemann, 1975.

13 Chamberlain G, Philipp E, Howlett B, Masters K. British births 1970. Vol. 2. Obstetric care. London: Heinemann, 1978.

14 Osborn A F, Morris A C. The rationale for a composite index of social class and its evaluation. Br J Sociol 1978; 30: $39-60$.

15 Everitt B S. The analysis of contingency tables. London: Chapman \& Hall, 1977.

16 Baker R J, Nelder J A. Generalised interactive modelling systems. London: Royal Statistical Society, 1977.

17 Fergusson D M, Horwood L J, Shannon F T, Taylor B. Parental smoking and lower respiratory illness in the first three years of life. J Epidemiol Community Health $1981 ; 35: 180-4$.

18 MacFarlane A, Fox F. Child deaths from accidents and violence. Popul Trends 1978; 12: 22-7.

19 Murdock R, Eva J. Home accidents to children under 15 years : survey of 910 cases. $B r$ Med J 1974; iii: 103-6.

${ }^{20}$ Sibert J R. Stress in families of children who have ingested poisons. $\mathrm{Br}$ Med J 1975; iii: 87-9.

21 Wadsworth J, Burnell I, Taylor B, Butler N R. Family type and accidents in preschool children. $J$ Epidemiol Community Health $1983 ; 31$ : in press.

22 Douglas J W B. Early hospital admissions and later disturbances of behaviour and learning. Dev Med Child Neurol 1975; 17: 456-80.

23 Gutelius M F, Kirsch A D, MacDonald S, Brooks M R, McErlean T, Newcomb C. Promising results from a cognitive stimulation program in infancy. Clin Pediatr (Phila) 1972; 21 : 585-93.

24 Osofsky H J, Osofsky J D. Adolescents as mothers: results of a program for low-income pregnant teenagers with some emphasis upon infant development. Am J Orthopsychiatry 1970; 40: 825-34.

Correspondence to Dr Brent Taylor, Department of Child Health, Royal Hospital for Sick Children, St Michaels Hill, Bristol BS2 8BJ.

Received 24 September 1982 